\title{
Social Interaction Research on Mobile Games: A Case Study of Peace Elite
}

\author{
Zhang Wenxin ${ }^{1}$ \\ ${ }^{1}$ the Chinese University of HongKong, Gender Study, Room 250, Sino Building, The Chinese University of Hong Kong, \\ Shatin, Hong Kong \\ *Zhang Wenxin. Email:1155120008@link.cuhk.edu.hk
}

\begin{abstract}
The scale of mobile game users is gradually expanding. Peace Elite is an extremely important MOBA mobile game as the inheritance and continuation of the PUBG Mobile in China. Social interaction in group confrontation and collaborative mobile games cannot be ignored. Based on the game mechanics of this game, this paper analyses the social networking of strangers and acquaintances from offline to online in the game from the perspective of acquaintances, teams and chat mechanisms. In addition, the paper analyses the reasons for this kind of social behaviour and compares its similarities and differences with real social interactions.
\end{abstract}

Keywords: gaming social interaction, virtual social interaction, Peace Elite

\section{Introduction}

In 2018, the number of mobile game users in China reached 554 million, mainly in first- and second-tier cities. For mobile game users, the focus is on people aged 35 and below, accounting for $84 \%$. At present, the users of the two major game companies in China, Tencent and Netease, are younger, and more than half of the game users are under 25 years old. In terms of game time, Glory of the King and PUBG Moblie (now Elite of Peace) made by Tencent are basically in the top three of the mobile game list.

In February 2018, the Lightspeed \& Quantum Studios Group of Tencent Games launched the competitive mobile game of PUBG. Since the early computer game of PUBG has accumulated a group of loyal players, the launch of mobile games has won a large number of players. In May 2019, the Peace Elite, which won the game version, was officially launched, translating the game scenes and user data in PUBG Mobile.

The social functions such as voice communication, team competition and confrontation embedded in the mobile game enrich and extend the connotation of mobile games. Peace Elite is an important and classic game with social functions.

\section{The stranger and acquaintance social interaction in the mobile game}

\section{1 game mechanics}

Peace Elite is a multiplayer online tactical competitive game that combines first-person and third-person shoot view. In the game, the player can control the role he plays, and win the game by defeating the opponents of the same game independently or in teams. In the Peace Elite, there are three systems of friends, team, and chat to support the player's social behaviour in the game.

Friends mechanism. Players could find the mobile QQ or WeChat friends playing this game in the friend system, and easily add them as game friends. At the same time, the players can also receive the application from strangers in the game chat system. After becoming a friend in the game, the player could give a certain amount of in-game items to the friend every day, and also obtain the game currency that from friends. After becoming a friend in the game, teaming up in the game improves the intimacy between the friends. After the intimacy reaches a certain value, players are able to choose to display the intimate relationship with the friends in the game. There are three intimate relationships of couple, friends and buddies can be chosen. These intimate relationships are displayed in the player's personal space in the game. At the same time, in the Peace Elite, the player have opportunity to choose another player to become his own master, and once mentoring team complete the game, they could get item rewards.

Team formation mechanism. Players choose to participate in the game independently or in the game. Players invite online game friends to join the game in the team interface, or invite mobile QQ or WeChat friends to enter the team. During the game, players are able to communicate with teammates by voice, text or expression. The game also provides common text information to make communication between teammates more convenient, such as "Fall in, come to me." Players post their team information in the lobby, legion, team, chat room and other channels to find teammates, or through recruitment to find gamers who also have same team needs.

Players build a legion by purchasing certain items in the game according to their needs. They can get game props 
by joining the legion and completing missions within the legion. Legion managers add other players to it, and other players in the legion can also recommend potential new members to the manager. Players also form teams in the game and get game props by being active in the team. Both the legion and the team can be bound to the WeChat group or the mobile QQ group, and members can easily enter the group through the in-game button.

Chat mechanism. In addition to the organization of the legion and the team, players also chat with other players in the world channel or chat room. Different chat rooms generally add tags according to demographic characteristics and behavioural characteristics of different interests, different genders, different ages, etc. Players can search specific chat rooms through tags or collect favourite chat rooms in the game.

\subsection{Acquaintances social: an extension of the offline acquaintance relationship}

To further understand the social behaviour of players in the Peace elite, the researchers found five Peace Elite players of different genders, ages, and cities of residence for a deep interview (see figure below). During the conversation, the researchers found that these players participated in the gaming social interactions to varying degrees, but they did not choose to "randomly match" teammates, but relied on a certain degree of acquaintance social relationships to launch online games. Different players have different social preferences in the game.

Table 1: Basic information of the interviewee

\begin{tabular}{|c|c|c|c|c|c|}
\hline Name & Lu & Shu & Ning & Chen & Shan \\
\hline Gender & Male & Female & Female & Male & Male \\
\hline Religion & $\begin{array}{c}\text { First-tier } \\
\text { cities }\end{array}$ & First-tier cities & overseas & $\begin{array}{c}\text { third-tier } \\
\text { cities }\end{array}$ & $\begin{array}{c}\text { Second-tier } \\
\text { cities }\end{array}$ \\
\hline Age & 24 & 16 & 24 & 18 & 20 \\
\hline Career & $\begin{array}{c}\text { Financial } \\
\text { practitioner }\end{array}$ & $\begin{array}{c}\text { Middle school } \\
\text { student }\end{array}$ & Postgraduate & $\begin{array}{c}\text { College } \\
\text { students }\end{array}$ & $\begin{array}{c}\text { Restaurant } \\
\text { waiter }\end{array}$ \\
\hline
\end{tabular}

Similar to other MOBA (Multiplayer Online Battle Arena) games run by Tencent, there are two common forms of acquaintances in this game. First, to form team with close friends in real life through social networks or offline ways, and form in-game intimacy. Second, is to play games with friends on social platforms such as WeChat and QQ friends in the game, which is often randomly. If the game shows that the team is online at the same time, players could invite the other team to play the game. After multiple teaming, the cooperation and contact in the game makes them become close friends from the ordinary acquaintance in reality.

In terms of game team objects, the respondents who are students are almost willing to become game friends with all WeChat and QQ friends who want to become friends with the game, while those who have already worked are more inclined to make game friends with acquaintances who have no work relationship. Additionally, they are not willing to make game friends with boss, clients who have clear interest relationship with them.

In terms of team formation, the respondents are all willing to play games with acquaintances than teaming up with strangers. However, the willingness is related to the game level and the degree of intimacy. For attempted and entertaining team decisions, intimacy is a major factor influencing the team's willingness. Under normal circumstances, especially intimate acquaintances who want to form a team, even if one of them is a complete novice, they will not refuse, but for the normal acquaintance, they will find an excuse to refuse. At the same time, the level of the player also has an impact on the attempted team decision. Generally speaking, the higher the opponent's level, the less likely the team request is rejected.

For the long-term, competitive team decision, the opponent's level is the main factor affecting the team's will. "If she is green hand, I am definitely not willing to team with them, unless she is my girlfriend." Chen's expression on this issue is somewhat representative. Players with medium ranks are more concerned at the grades because they are more worried that players with lower levels will affect their performance, and they will not have enough confidence to believe that they can carry others.

The acquaintance social interaction embodied in the Peace Elite is essentially an online extension of the offline acquaintance relationship. Students tend to embrace the relationship between acquaintances and semiacquaintances, and are curious and explored about the whole social network. The professionals also evade the pressure relationship in real life and avoid socializing with the authority and stakeholders. For intimate relationships, acquaintance still occupy a more important position in the game. This relationship can break through the level of the game itself, and the game can be used to consolidate intimacy. Games such as the Peace Elite, which require teamwork and provide communication in the form of voice and text, provide opportunities for intimacy in the semiacquaintance relationship that is formed by the opportunity.

\subsection{Strangers social interaction: Interest- oriented in cyber world}

In addition to acquaintances, some players will also get strangers social interaction in the Peace Elite. As the name 
suggests, the stranger's social interaction in the game refers to the behaviour of the player forming a social relationship with other players who are not familiar in real life.

Game Scholar Richard Battier has divided online game players into four categories according to the player's behaviour and focus ${ }^{1}$. Exploratory players: be interested in game world, and try to understand the game's operating rules and the game world; social players: be optimistic on socialize with other players, regard the game as a channel for social interaction; achievement players: mainly pursue achievements and levels in the game world; killer player: be raptures over attacking other player or exerting influence on other players to get fun.

As an online game, the Peace Elite can be easily divided into these four categories. Exploratory players pay attention to different environments of different regional maps in different modes in the game; social players prefer to communicate with teammates during the game; achievements players may prefer to collect items such as costumes in the game or get a higher segment achievement; killer players prefer to kill other players in the battle and win.

According to this, there are different types of social behaviours among strangers in the game.

Through interviews, it is known that the original intention of typical social player is leisurely entertainment with friends and to cooperate with the teammates in the game. There are two kinds of social interactions of such players in the game. The first one is more conventional: find teammates from world channel, the legion and the team. if the other side is willing to cooperate or skilful, they will be willing to form a game with them. Another way is to join the group of Peace Elite players in the same school or in the same city, accept the invitation of the group friends to play the game, and usually carry out some daily conversations in the group. Once they are familiar with the friends in the game, they will develop a more realistic relationship with each other, such as adding WeChat friends or QQ friends and conducting daily communication. Exploratory players are relatively indifferent to the strangers in the game, and are more inclined to study the coping strategies of different situations in the game. Although teaming up with strangers, they have more stable game teammates. The demand of teammates for such players is the level of the game. Besides, there is very little communication with teammates for this kind of players outside the game.

Achievement players pay attention to the collection of their own game segments and costumes. Players who pay attention to their own levels hardly play with strangers in Peace Elite. Although having tried to team up with strangers, they believe that it is passive for levels due to poor communication and lack of understanding, resulting a regular team game with acquaintances.

The players who pay attention to the collection of costume props are mainly women, tend to socialize with strangers in the game, and even form game couples with strange players. The game couples will generate the behaviour of gifts giving and game companion. In addition to the intimate relationship within the game, the game couple also have more communication outside the game, involving all aspects of daily life, and even plan to meet in real life.

Because of valuing the success and failure of the game, the killer player has certain advantages in game skills and game achievements, and it is easy to get the dependence of the opposite gender in the game, which means they are easily to find a game couple.

The stranger social interaction in the game have certain similarities with reality world, and to some extent, it can constitute an alternative satisfaction for social interaction in the reality. The stranger social interaction in the game is influenced by the player's behaviour, the resources and abilities (personal skills, cooperation awareness, payment ability) are the main driving force for the selection of the players. At the same time, the influence of the community plays a major role in the social behaviour of the stranger in the game.

\section{ANALYSIS OF GAME SOCIAL BEHAVIOR}

Based on interviews, we found some similarities and differences between the social behaviour in the game and offline of players.

Part of the social behaviour of the player in the game is an extension of the offline social reality ${ }^{2}$. The combination of the game and the virtual community, acquaintance social software provides a new social scene where people can entertain and socialize with their real-life acquaintances in the game. Therefore, online socialization may promote people's offline social reality to provide more scenes and communication content ${ }^{3}$.

There is a certain similarity between the player's social behaviour in the game and the offline social reality ${ }^{4}$.

First, online social sides pay attention to the resources in virtual community, which is similar to the offline world. Generally speaking, in the game, most of the player's demographic characteristics such as gender, age, income and other factors will not be revealed, and even can be hidden, but players in the game will also tend to consider the other side's ability in the game (such as the rank level), resources (such as paying ability), appearance (such as the richness of skin and decorative items) and popularity (such as the home page $)^{5}$. In the online relationship of light involvement, the attention of the players will be biased towards the relevant factors of the game itself, such as the game skills; while in the high involvement online relationship, such as adding the acquaintance social account or having a game couple, they will pay more attention to in-game resource factors, such as payment ability, which are more related to real social resources. Popularity is related to the player's own appearance factors (game avatar) and in-game activity, so it will also become an important factor influencing some male players for high involvement online relationship. The appearance of the characters in the game is often related to the player's paying ability, so it will become a consideration for some female players on the relationship of high involvement. 
Second, in online social activities in the game, people tend to make friends who have similar background or demographic characteristics, which is similar to offline world ${ }^{6}$. In the online game, many people still tend to chat in the same city channel, and team up with the same city players. Moreover, players are more likely to add other players in the same school, community, or internal game group of some organizations as game friends than other players who are completely unfamiliar. The geosocial model does not disappear completely ${ }^{7}$.

Since in-game socialization belongs to virtual community socialization, there are also some differences between online social and offline social interaction.

Relying on the vitality and the high mobility of the participants in the virtual community, there is also some instability in the online social interaction in the game. People are less inclined to trust each other, which leads to stranger interaction by the geographical and real social relationships ${ }^{8}$. However, this situation has also changed with the degree of influence to people in different eras by the Internet. For example, when asked about "Do you worry about being deceived in the game by getting game couple", many respondents said that this is It is a small probability event, the other one should enter the game for leisure and entertainment other than deceiving. And they mentioned that there are also situations of deceitful feelings in real life, so they believe that as long as paying attention to their own security, they could get a stable relationship on the Internet ${ }^{9}$.

Relying on the openness and professionalism of the virtual community, there is a certain difference in the development process of online offline social interaction ${ }^{10}$. For example, the players of Peace Elite has a natural topic - about game itself, and because of the material incentives and association with social network platforms, the relative acquaintance process is faster. However, due to openness and vitality, the process of developing a mutually trustworthy relationship from a relatively acquaintance is slower than the offline reality.

In addition, the phenomenon of game couple that occurs in the game social interaction is different from the online love that appeared in emerging Internet time. Most people use social software to develop relationships for the purpose of finding lovers. Although there are couple relationships in the game for the purpose of lover-finding, many of them develop from friends with common interests. The game love has something in common with traditional offline love relationships based on common hobbies. Both sides may also have online common circle of friends. Compared to traditional cyberlove to develop relationships for the purpose of love, it is of high stability for game couples.

\section{SUMMARY}

Peace Elite is a typical MOBA game, whose team confrontation mode makes it naturally get certain social attributes. In addition, it is developed and operated by social overlord Tencent, and is connected with the current two major social platforms, WeChat and QQ, which makes Peace Elite more obvious in social attributes. The virtual social interaction in the game extends the boundary of real social interactions, and has a certain degree of relevance to real social. However, it also has its own unique virtual game attributes, which realizes the combination of strangers and acquaintances social interaction.

\section{REFERENCES}

[1] Wang Jiyu. (2011). Psychological appeals of online game players. Journal of Nanjing University of Posts and Telecommunications (Social Science Edition), (2), 20-24.

[2] Pearce, C., Artemesia, Boellstorff, T., \& Nardi, B. A. (2011;2009;). Communities of play: Emergent cultures in multiplayer games and virtual worlds. US: The Mit Press.

[3] Wu Yufei. (2012). Social Network Games Change Human Life - - Social Network Games from the Perspective of Cultural Function Theory. Journal of Beijing University of Posts and Telecommunications: Social Science Edition, 14(1), 7-11.

[4] Kong Shaohua. (2014). Review of foreign mmorpg virtual world research. Information Science, 32(3), 150155.

[5] Nurdin Zunong, Wang Wenhong, Huang Pei, ZUNONGNu-er-ding, WANGWen-hong, \& HUANGPei. (2014). Research on the development status and development trend of online social games. Journal of Beijing University of Posts and Telecommunications (Social Science Edition) ), 16(1), 8-12.

[6] Lee, H. R., \& Jeong, E. J. (2017). Therapeutic role of player self-efficacy in online gaming. Social Behavior and Personality: An International Journal, 45(9), 1475-1484.

[7] Wang Weiwei. (2017). Social Communication and Analysis of Mobile Games: A Case Study of Tencent's Game "Glory of the King". Communication Research (05), 59.

[8] Lee, H. R., \& Jeong, E. J. (2018). Do therapeutic interventions exist in online games? effects of therapeutic catharsis, online game self-efficacy, and life self-efficacy on depression, loneliness, and aggression. International JOURNAL OF CONTENTS, 14(1), 12-17.

[9] Bhagat S, Jeong EJ, Kim DJ. The Role of Individuals' Need for Online Social Interactions and Interpersonal Incompetence in Digital Game Addiction. International Journal of Human-Computer Interaction. 2019:1-15. 
[10] Lee, S. J., Jeong, E. J., \& Jeon, J. H. (2019). Disruptive behaviors in online games: Effects of moral positioning, competitive motivation, and aggression in "League of legends". Social Behavior and Personality: An International Journal, 47(2), 1-9. 